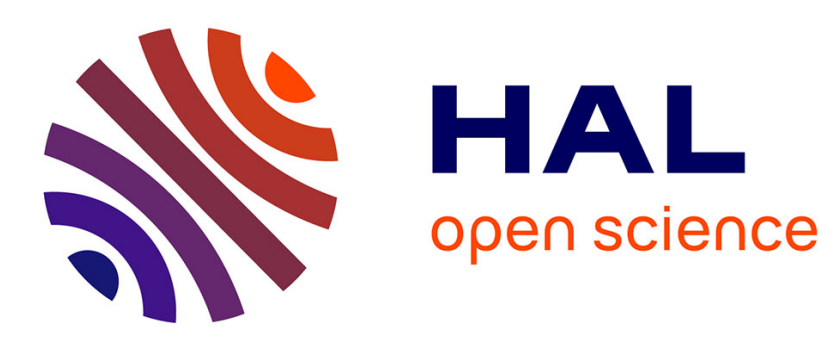

\title{
$\gamma$-Fluorinated analogues of glutamic acid and glutamine
}

R. Dave, B. Badet, Patrick Meffre

\section{To cite this version:}

R. Dave, B. Badet, Patrick Meffre. $\gamma$-Fluorinated analogues of glutamic acid and glutamine. Amino Acids, 2003, 24 (3), pp.245-261. 10.1007/s00726-002-0410-9 . hal-02002676

\section{HAL Id: hal-02002676 https://hal.science/hal-02002676}

Submitted on 11 Feb 2019

HAL is a multi-disciplinary open access archive for the deposit and dissemination of scientific research documents, whether they are published or not. The documents may come from teaching and research institutions in France or abroad, or from public or private research centers.
L'archive ouverte pluridisciplinaire HAL, est destinée au dépôt et à la diffusion de documents scientifiques de niveau recherche, publiés ou non, émanant des établissements d'enseignement et de recherche français ou étrangers, des laboratoires publics ou privés. 


\section{$\gamma$-Fluorinated analogues of glutamic acid and glutamine}

\section{Review Article}

\author{
R. Dave ${ }^{1}$, B. Badet ${ }^{2}$, and P. Meffre ${ }^{1}$ \\ ${ }^{1}$ UMR 7573-C.N.R.S., ENSCP, Paris, France \\ ${ }^{2}$ UPR 2301-CNRS, ICSN, Gif-sur-Yvette, France
}

\begin{abstract}
Summary. $\gamma$-Fluorinated analogues of glutamic acid and glutamine are compounds of biological interest. Syntheses of such compounds are extensively reviewed in this article. 4-Fluoroglutamic acid was prepared as a mixture of racemic diastereomers by Michael reaction, inverse-Michael reaction or by electrophilic / nucleophilic fluorination. Optically enriched 4-fluoroglutamic acids were obtained by several resolution techniques as well as by asymmetric methodologies using the chiral pool. 4-Fluoroglutamine was prepared as a mixture of stereoisomers as well as in racemic erythro and threo forms from the corresponding 4-fluoroglutamic acids using aminolysis and conventional protection and deprotection strategies. Racemic 4,4-difluoroglutamic acid was synthesized by a nitroaldol reaction and its L-enantiomer obtained via three different asymmetric routes. Racemic 4,4-difluoroglutamic acid was converted into the corresponding 4,4-difluoroglutamine using a protection / aminolysis / deprotection sequence while N-Boc-L4,4-difluoroglutamine was prepared directly from $(R)$-Garner's aldehyde using a Reformatsky reaction as the key step.
\end{abstract}

Keywords: Glutamine - Glutamine-dependent amidotransferase $\gamma$-Fluorinated glutamic acid - $\gamma$-Fluorinated glutamine -4 Fluoroglutamic acid - 4-Fluoroglutamine - 4-Fluoromethotrexate $\gamma, \gamma$-Difluorinated glutamic acid $-\gamma, \gamma$-Difluorinated glutamine 4,4-Difluoroglutamic acid - 4,4-Difluoroglutamine - 4,4Difluoromethotrexate

Abbreviations: Ac, acetyl; ACN, acetonitrile; Boc, tertbutyloxycarbonyl; $\mathrm{Bu}_{2} \mathrm{BOTf}$, dibutylboron triflate; $\mathrm{CbzCl}$, benzyl chloroformate; CTT, 2-chloro-1,1,2-trifluorotriethylamine; DAST, (diethylamino)sulfur trifluoride; DEAD, diethylazodicarboxylate; DHFR, dihydrofolate reductase; DIEA, diisopropylethylamine; DMAP, dimethylaminopyridine; DMP, dimethoxypropane; EDC, ethylene dichloride; 4-FGlu, 4-fluoroglutamic acid; 4,4-F2Glu, 4,4-difluoroglutamic acid; 4,4-F2MTX, 4,4-difluoromethotrexate; 4-FMTX, 4-fluoromethotrexate; FPGS, folylpoly- $\gamma$-glutamate synthetase; Glu, glutamic acid; Gn, glutamine; Gn-AT, glutaminedependent amidotransferase; $\mathrm{HCl}$, hydrochloric acid; HPLC, high performance liquid chromatography; HQ, hydroquinone; LDA, lithium diisopropylamide; $\mathrm{MeOH}$, methanol; MTX, methotrexate; MTPA, $\alpha$-methoxy- $\alpha$-(trifluoromethyl)phenylacetic acid; NBS,
N-bromosuccinimide; NFSi, N-fluorobenzenesulfonimide; NMR, nuclear magnetic resonance; 2-PrOH, isopropanol; PTSA, ptoluenesulfonic acid; TCDI, thiocarbonyldiimidazole; TEMPO, 2,2,6,6-tetramethyl piperidine-1-oxyl; TFA, trifluoroacetic acid.

\section{Introduction and goals}

It is well recognized that replacing a hydrogen atom by a fluorine atom in a chemical entity can bring significant changes in its chemical and biochemical behaviour. Fluorine, due to its strong electron withdrawing effect (with reduced steric requirements) can have noticeable consequences on the electron distribution and subsequently on the acidity or basicity of the neighbouring group thereby changing the overall reactivity and stability of the molecule.

These impacts of fluorine atoms in biologically relevant molecules, especially in amino acids, can be advantageously exploited to lead to potent therapeutic agents through proper understanding of some biochemical properties such as:

- identification of binding sites with naturally occurring macromolecules such as enzymes, receptors, etc...

- increasing resistance to metabolic transformation due to the strong carbon-fluorine bond.

- investigation of recognition properties, mechanism and structure of enzymes through modification of the chemical reactivity with the use of fluorinated compounds as biological tracers and as mechanistic probes. 
Introduction of fluorine atom at the C-4 position of glutamic acid has been realized in the screening of modulators for folate poly- $\gamma$-glutamate biosynthesis and to study the role of analogous derivatives of antifolates such as methotrexate (MTX) in the cytotoxic action of these drugs. In one of the crucial steps, the $\gamma$-carboxyl group of the C-terminal glutamate is activated by the enzyme prior to peptide coupling. Therefore, introducing one or more fluorine atoms in the $\alpha$ position with respect to the $\gamma$-carboxyl side chain could interfere with such biological processes (Hart et al., 1996; Tsukamoto et al., 1996). As a second illustration, enantiomerically pure 4-fluoroglutamic acids were employed for investigating the mechanism of the vitamin K-dependent carboxylation of glutamic acid residues present in several proteins (Dubois et al., 1983).

Glutamine, the most abundant amino acid in the body, was originally classified as a "non-essential" amino acid. However, it is now considered as "conditionally essential" particularly after clinical trauma such as major surgery or burns (Castell and Newsholme, 2001). It was established in the early 1980s that glutamine is an important fuel for some key cells of the immune system (Ardawi and Newsholme, 1983).

In living cells, glutamic acid and glutamine are the main storage forms of nitrogen for the synthesis of macromolecules. While glutamate is able to deliver its $\alpha$-amino group by transamination, labilisation by amide bond cleavage of glutamine $\delta$ nitrogen requires intervention of the catalytic machinery of glutamine-dependant amidotransferases (Gn-AT). Glucosamine-6-phosphate synthase, one of the Gn-AT, is involved in the biosynthesis of D-glucosamine 6-phosphate. The considerable involvement of D-glucosamine 6-phosphate synthase in a number of biological processes such as the biosynthesis of bacterial peptidoglycane or fungal cell wall and its potential as a therapeutic target in type-2 diabetes, requires the precise understanding of its mechanism at the molecular level (Massière and Badet-Denisot, 1998; Teplyakov et al., 2002). It was hypothesised that fluorinated analogues of glutamine, particularly with fluorine in the $\alpha$-position to the amide group, might interfere with the normal nitrogen transfer processes providing the basis for possible therapeutic agents.

Several reviews dealing with the synthetic aspects of different classes of fluorinated amino acids have

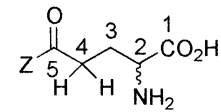

$\mathrm{Z}=\mathrm{OH}$; Glutamic acid

$\mathrm{Z}=\mathrm{NH}_{2} ;$ Glutamine

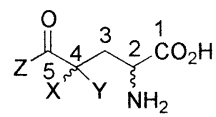

$X=F, Y=H$ and $Z=O H ;$ 4-fluoroglutamic acid

$X=F, Y=H$ and $Z=\mathrm{NH}_{2} ;$ 4-fluoroglutamine

$\mathrm{X}=\mathrm{F}, \mathrm{Y}=\mathrm{F}$ and $\mathrm{Z}=\mathrm{OH}$; 4,4-difluoroglutamic acid $X=F, Y=F$ and $Z=\mathrm{NH}_{2} ; 4,4$-difluoroglutamine
Fig. 1. Glutamic acid, glutamine and $\gamma$-fluorinated glutamic acids and glutamines

emerged in the area of fluorine chemistry. "Synthesis of $\gamma$-fluoro- $\alpha$-amino acids" (Haufe and Kroger, 1996), "Syntheses of fluorinated amino acids: from the classical to the modern concept" (Tolman, 1996) and "Synthesis of fluorinated amino acids" (Sutherland and Willis, 2000) are among the most recent ones. Kukhar and Soloshonok (Kukhar and Soloshonok, 1995) have comprehensively reviewed the syntheses and properties of fluorinated amino acids. Welch and Hudlicky have surveyed the general fluorination methodologies to account for the increasing interest of biochemists in fluoro compounds, reflected by an increasing number of relevant publications, particularly at the interface of fluorine/bioorganic chemistry (Welch, 1991; Hudlicky, 1992). Although these reviews discuss in depth the chemistry of different classes of fluorinated compounds, there has not been much emphasis on the synthetic aspects of $\gamma$ fluorinated glutamic acid and glutamine (Fig. 1). The present review discusses the syntheses of $\gamma$-fluorinated glutamines and glutamic acids described to date, with particular emphasis on asymmetric pathways and strategies of resolution of stereoisomers leading to $\gamma$-fluorinated compounds in diastereo- and enantiomerically enriched forms.

\section{Syntheses of 4-fluoroglutamic acid 1 and 4-fluoroglutamine 2}

The presence of two stereocentres in 4-fluoroglutamic acid $\mathbf{1}$ and 4-fluoroglutamine $\mathbf{2}$ implies that they exist as two diastereomeric pairs of enantiomers as depicted in Fig 2.

\subsection{4-Fluoroglutamic acid 1}

Several methods for the preparation of 4fluoroglutamic acid $\mathbf{1}$ in racemic and enantiomerically pure form have been described in the literature. 


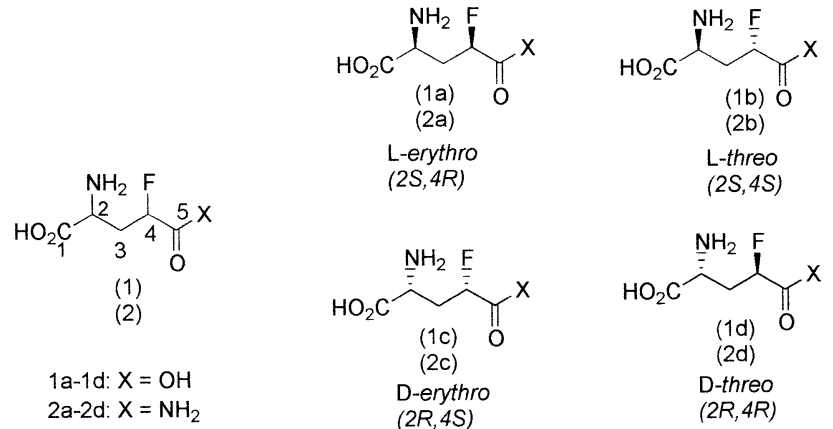

Fig. 2. Stereoisomeric forms of 4-fluoroglutamic acid $\mathbf{1}$ and 4fluoroglutamine 2

\subsubsection{Preparations of 4-fluoroglutamic acid $\mathbf{1}$ as a} mixture of stereoisomers

4-Fluoroglutamic acid 1 was prepared by Michael reaction, inverse Michael reaction or by using different electrophilic fluorinating agents.

\section{a) Michael reaction}

In 1960, Hudlicky reported the first synthesis of 4fluoroglutamic acid $\mathbf{1}$ in racemic form by a Michael reaction. Historically, it is the first synthesis of any monofluorinated aliphatic amino acid. Ethyl $\alpha$-fluoro acrylate 5 was subjected to Michael addition with diethyl acetamidomalonate $\mathbf{6}$ to yield ethyl $\alpha$ carboethoxy- $\alpha$-acetamido- $\gamma$-fluoroglutarate 7 , which on acid hydrolysis followed by neutralisation with silver oxide gave 4-fluoroglutamic acid $\mathbf{1}$ in $31 \%$ overall yield based on 5 (Hudlicky, 1960; 1961). The limitation of the approach was however the poor accessibility to the Michael acceptor 5 which was obtained in a poor $10 \%$ yield by a two-step procedure starting from ethyl $\alpha, \alpha, \beta$-tribromopropionate $\mathbf{3}$. Upon fluorination with mercurous fluoride and iodine, 3 yielded ethyl $\alpha, \beta$-dibromo- $\alpha$-fluoropropionate $\mathbf{4}$, which on subsequent dehalogenation with zinc gave ethyl $\alpha$-fluoroacrylate 5 (Scheme 1).

4-Fluoroglutamic acid $\mathbf{1}$ was found to slightly inhibit the growth of Mycobacterium tuberculosis at a concentration of $50 \mu \mathrm{g} / \mathrm{mL}$ over one week incubation.

Tolman and Veres improved the synthesis of

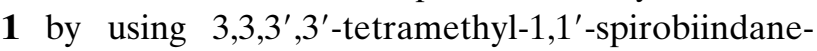
$5,6,5^{\prime}, 6^{\prime}$-tetrol as a stabilizer for the Michael acceptor 5. With this additive, which is more stable in alkaline medium than hydroquinone, the yield of the Michael adduct 7 was enhanced by $21 \%$ (Tolman and Veres, 1967).

Later on, the same authors optimised both the preparation and the reaction of the Michael acceptor to prepare 4-fluoroglutamic acid $\mathbf{1}$ on multigram scale. Ethyl 2-fluoroacrylate $\mathbf{5}$ of high purity was first prepared in quantitative yield by vacuum distillation of a mixture of potassium phthalimide and ethyl 2 - fluoro - 3 - (4' - toluenesulphonyloxy)propionate (Tolman and Spronglova, 1983; Tolman and Veres, 1964). Freshly prepared ethyl 2 -fluoroacrylate 5 was then immediately subjected to Michael addition with diethyl acetamidomalonate $\mathbf{6}$ to afford the adduct $\mathbf{7}$ in $80-88 \%$ yield. Acid hydrolysis followed by neutralisation with pyridine and addition of ethanol gave crystalline 4-fluoroglutamic acid $\mathbf{1}$ in yields as high as $80 \%$ (Tolman, 1993). With these refinements of the method, multigram quantities of 4-fluoroglutamic acid 1 were prepared.

\section{b) Inverse-Michael reaction}

Using diethyl fluoromalonate $\mathbf{1 0}$ as Michael donor, Buchanan et al. advantageously inverted the Michael substrates in the original synthesis reported by Hudlicky (Hudlicky, 1960 and 1961). Diethyl fluoromalonate $\mathbf{1 0}$ was added to ethyl $\alpha$-acetamidoacrylate 11 to yield diethyl $\alpha$-acetamido- $\alpha^{\prime}$-carboethoxy- $\alpha^{\prime}$ fluoroglutarate $\mathbf{1 2}$ in good yield along with a small amount of 3,5-dicarboethoxy-3-fluoro-2-pyrrolidone, due to ring closure. The mixture was subjected to acid hydrolysis then neutralized with silver oxide to give 4fluoroglutamic acid 1 in $56 \%$ overall yield based on diethyl fluoromalonate 10 (Buchanan et al., 1962) (Scheme 2).
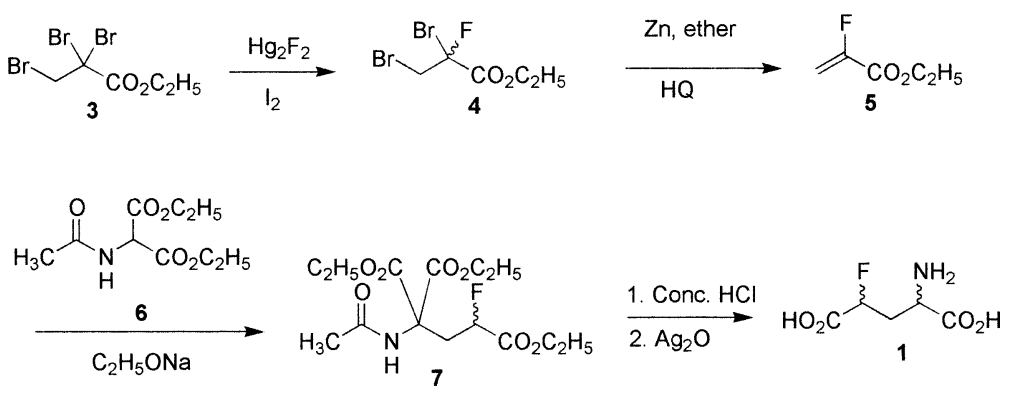

Scheme 1. First synthesis of 4-fluoroglutamic acid $\mathbf{1}$ 

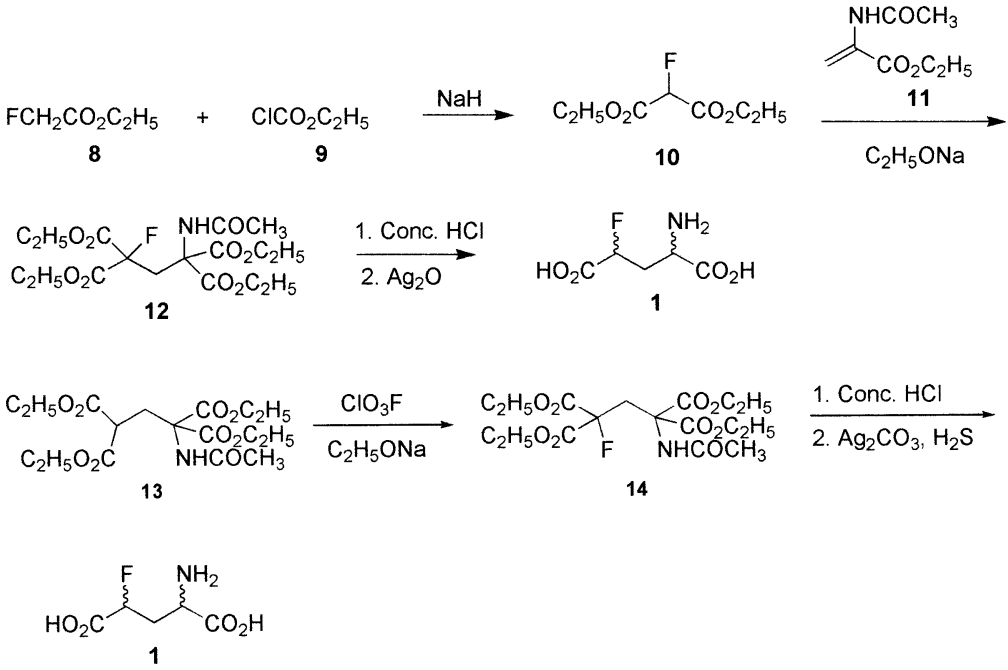

Scheme 2. Synthesis of 4-fluoroglutamic acid $\mathbf{1}$ by inverse Michael reaction

Scheme 3. Synthesis of 4-fluoroglutamic acid $\mathbf{1}$ by electrophilic fluorination

The key Michael donor, diethyl fluoromalonate 10 was prepared from ethyl fluoroacetate $\mathbf{8}$ and ethyl chloroformate 9 in $24 \%$ yield.

c) Fluorination

Perchloryl fluoride $\left(\mathrm{ClO}_{3} \mathrm{~F}\right)$ and 2-chloro-1,1,2trifluorotriethylamine (CTT) have been used as the electrophilic and nucleophilic fluorinating agents respectively for the preparation of 4-fluoroglutamic acid $\mathbf{1}$.

- Using perchloryl fluoride: Alekseeva et al. developed a novel and concise approach to synthesis of 4fluoroglutamic acid $\mathbf{1}$ using electrophilic fluorination of the appropriately substituted tetraester $\mathbf{1 3}$ with perchloryl fluoride $\left(\mathrm{ClO}_{3} \mathrm{~F}\right)$. The starting substance, tetraethyl 1-acetamido-1,1,3,3 propanetetracarboxylate $\mathbf{1 3}$ was obtained by condensation of malonic ester with paraformaldehyde and diethyl acetamidomalonate using a known literature procedure (Kaneko et al., 1962). The treatment of the sodium salt of $\mathbf{1 3}$ with perchloryl fluoride $\left(\mathrm{ClO}_{3} \mathrm{~F}\right)$ gave tetraethyl 1acetamido-3-fluoro-1,1,3,3-propanetetracarboxylate 14 in $70-75 \%$ yield. Following acid hydrolysis and decarboxylation, 14 afforded 4-fluoroglutamic acid hydrochloride, directly converted into free amino acid by silver carbonate. Excess of silver was removed as silver sulfide by action of hydrogen sulfide and 4-fluoroglutamic acid 1 was obtained in $83-88 \%$ yield based on the fluorinated tetraester derivative $\mathbf{1 4}$ (Alekseeva et al., 1967) (Scheme 3).

At the same time, Tolman and Veres also independently reported, a similar synthesis of 4-fluoroglutamic acid 1 by electrophilic fluorination of tetraethyl 1-acetamido-1,1,3,3-propanetetracarboxylate $\mathbf{1 3}$ with perchloryl fluoride $\left(\mathrm{ClO}_{3} \mathrm{~F}\right)$ (Tolman and Veres, 1966). Although the procedure employed by these authors was short and relatively better than the former, the major hurdle was the safety hazards involved in the fluorination step, particularly when the reactions were carried out on a large scale.

- Using 2-chloro-1,1,2-trifluorotriethylamine (CTT): The best way to resolve the hazards involved in the fluorination step was to switch to a safer fluorinating agent. Bergmann and Chun-Hsu synthesised 4fluoroglutamic acid $\mathbf{1}$ using CTT-mediated nucleophilic fluorination of an appropriately substituted hydroxyl compound 19. Etherification of ethyl 3chloro-2-hydroxypropionate $\mathbf{1 5}$ with isobutylene afforded the ether derivative $\mathbf{1 6}$ which was condensed with diethyl acetamidomalonate 17. The ether group of the adduct $\mathbf{1 8}$ was hydrolysed and the deprotected alcohol group was substituted by fluorine using CTT 20. The fluorine derivative $\mathbf{2 1}$ was then hydrolysed, decarboxylated and neutralised with silver oxide to give 4-fluoroglutamic acid $\mathbf{1}$ in $15 \%$ overall yield based on 15 (Bergmann and Chun-Hsu, 1973) (Scheme 4).

All the existing procedures afforded 4fluoroglutamic acid $\mathbf{1}$ as an uncontrolled mixture of stereoisomers. Generally, for biochemical studies, stereochemically pure materials are more informative.

1.1.2 Preparations of enantiomerically enriched 4-fluoroglutamic acid (1a-1d)

Asymmetric syntheses and resolution techniques coupled with enzymatic reactions have been 
extensively used to obtain all the four stereoisomers of 4-fluoroglutamic acid $\mathbf{1 .}$

\subsubsection{Resolution methods}

1.1.2.1.1 L-erythro and L-threo-4-fluoroglutamic acid (1a \& 1b)

L-threo and L-erythro-4-Fluoroglutamic acid have been resolved from their racemic mixtures by two different strategies.

a) By ion-exchange chromatography and aminopeptidase resolution: Marquet prepared optically pure L-erythro-4-fluoroglutamic acid 1a and L-threo-4fluoroglutamic acid $\mathbf{1 b}$ by resolution of racemic 4-
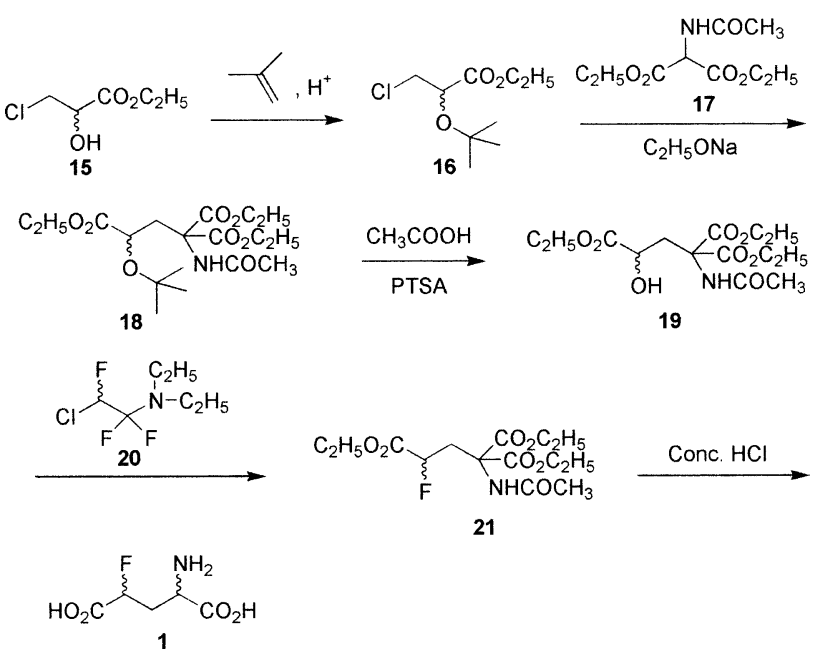

Scheme 4. Bergmann's synthesis of 4-fluoroglutamic acid $\mathbf{1}$

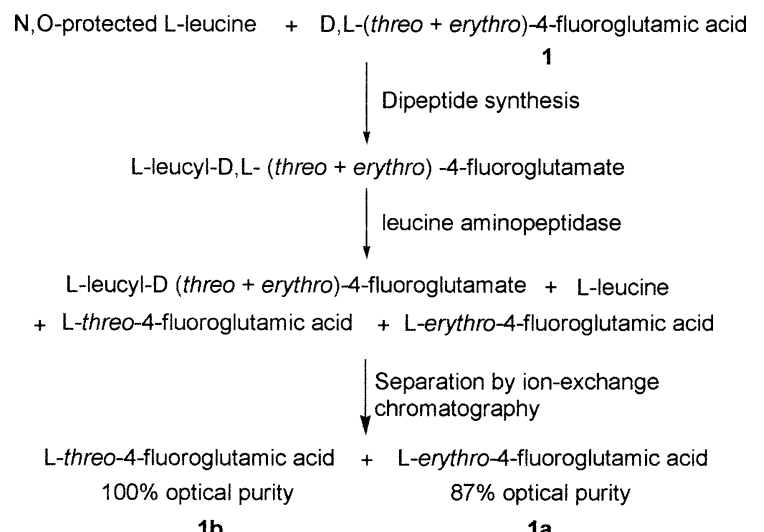

Fig. 3. Preparation of optically pure L-threo-4-fluoroglutamic acid 1b fluoroglutamic acid $\mathbf{1}$ using anion exchange chromatography coupled with an enzymatic reaction (Dubois et al., 1983). 1 was prepared using the Michael reaction described above (Buchanan et al., 1962; Hudlicky, 1960 and 1961) and converted into L-leucylD,L-(threo +erythro)-4-fluoroglutamate by coupling with N,O-protected L-leucine (Fig. 3). The dipeptide mixture was resolved with leucine aminopeptidase into a mixture of L-threo- and L-erythro-4fluoroglutamates. Ion-exchange chromatography allowed separation of optically pure L-threo-4fluoroglutamic acid $\mathbf{1 b}$ and L-erythro-4-fluoroglutamic acid $1 \mathbf{a}$ in $87 \%$ ee as determined by HPLC (Bory et al., 1984).

As L-erythro-4-fluoroglutamic acid 1a was not obtained in high optical purity, an alternative approach was used. The mixture of racemic diastereomers of 4-fluoroglutamic acid $\mathbf{1}$ was separated into D,L-erythro and D,L-threo-4-fluoroglutamic acid by the ion-exchange method. Chromatographically pure D,L-erythro-4-fluoroglutamic acid (1a $+\mathbf{1 c )}$ was converted to L-leucyl-D,L-erythro-4-fluoroglutamate. L-Leucyl-L-erythro-4-fluoroglutamate was isolated by ion-exchange chromatography and hydrolysed by leucine amidopeptidase to give optically pure Lerythro-4-fluoroglutamic acid 1a as shown by HPLC (Fig. 4) (Bory et al., 1984).

Actually, Unkeless and Goldman previously used this methodology to obtain L-threo-4-fluoroglutamic

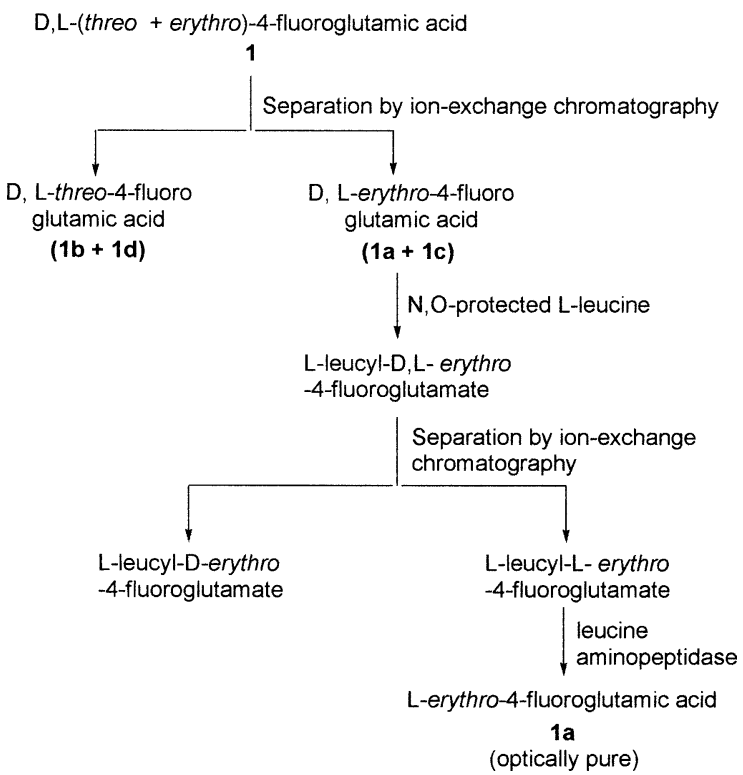

Fig. 4. Preparation of optically pure L-erythro-4-fluoroglutamic acid 1a 
acid $\mathbf{1 b}$ and L-erythro-4-fluoroglutamic acid 1a (Unkeless and Goldman, 1970 and 1971), but the authors did not report the optical rotations and NMR data of the compounds.

With the emergence of this first report on the resolution of 4-fluoroglutamic acid $\mathbf{1}$, Tolman realized the importance of analytical techniques to determine the sterochemical composition of 4-fluoroglutamic acid 1 samples. The known quantitative cyclization of diethyl 4-fluoroglutamate into a pyrrolidone derivative at high temperature was advantageously exploited to develop an elegant GC method. 4-Fluoroglutamic acid 1 was esterified and injected directly into the injection port at the temperature range of 190 to $230^{\circ} \mathrm{C}$ allowing separation of erythro and threo isomers on several types of columns (Tolman et al., 1984). Soon after, Azerad reported gas chromatography resolution of the four stereoisomers as their N-trifluoroacetyl diisopropyl esters (Maurs et al., 1985).

b) Recrystallisation and aminoacylase resolution: Kawada et al. also reported the resolution of L-threo and L-erythro-4-fluoroglutamic acid by controlled crystallisation of $\mathrm{N}$-acyl derivatives followed by enzymatic reaction. They claimed that the resolution method is practical and safe for large-scale preparations. The procedure involves the conversion of racemic 4-fluoroglutamic acid $\mathbf{1}$ to N-chloroacetyl4-fluoroglutamic acid 5-methyl ester 22, followed by recrystallisation from 2-butanone to afford D,Lerythro enriched (erythro $>99 \%$ ) $\mathbf{2 3}$ and D,L-threo enriched (threo:erythro 94:6) $\mathbf{2 4}$ diastereomers in 47 and $54 \%$ yield, respectively. Subsequent enzymatic resolution of the separated diastereomers using aminoacylase at $\mathrm{pH} 6.0$ gave enantiomerically pure L-isomers in $86 \%$ yield after ion-exchange column chromatography (Kokuryo et al., 1996) (Scheme 5).

\subsection{Resolution of all four stereomers of 4-fluoroglutamic acid (1a-1d)}

Tolman et al. prepared all four stereomers of 4fluoroglutamic acid $\mathbf{1}$ in more than $97 \%$ optical purity. L-erythro, D-erythro and L-threo-4-Fluoroglutamic acid (1a, 1c \& 1b) were resolved by preferential crystallisation of appropriately derivatised $\mathbf{1}$ while the fourth stereomer, D-threo-4-fluoroglutamic acid 1d required an additional enzymatic resolution step.

4-Fluoroglutamic acid 1 was esterified with $\mathrm{HCl} /$ methanol and recrystallised from methanol/ether to give the hydrochloride salt of dimethyl 4fluoroglutamate enriched in the erythro form (crop 1). Mother liquors were concentrated and crystallised twice from methanol/ether to give a second crop (crop 2) of ester salt derivative enriched in the erythro form. As further treatment of the mother liquors gave the threo isomer in less than $92 \%$ optical purity, an alternative effective way was developed.

Thus, the mother liquors were concentrated and subjected to acid hydrolysis to give a mixture of erythro and threo 4-fluoroglutamic acid in approximally $1: 2$ ratio. 4-Fluoroglutamic acid enriched in the threo form was esterified with 2-propanol/ $\mathrm{HCl}$ and crystallised from acetone to give threo enriched diisopropyl 4-fluoroglutamate salt (crop 3). Mother liquors were concentrated and recrystallized again to give another crop of threo enriched isomer (crop 4). The two crops of erythro (crop 1 and 2 ) and threo (crop 3 and 4 ) enriched isomers were individually combined and recrystallised from methanol/ether and acetone, respectively. Finally, the ester derivatives of the erythro and threo isomers were hydrolysed and neutralised with pyridine to afford diastereomerically pure erythro 4-fluoroglutamic acid (1a $+\mathbf{1 c})$ and threo 4fluoroglutamic acid $(\mathbf{1 b}+\mathbf{1 d})$ in 54 and $52 \%$ overall yield, respectively, based on 1 (Fig. 5) (Tolman et al., 1993).

Tolman and Simek further pursued the resolution of erythro and threo 4-fluoroglutamic acid into their individual enantiomers by using chiral amines.

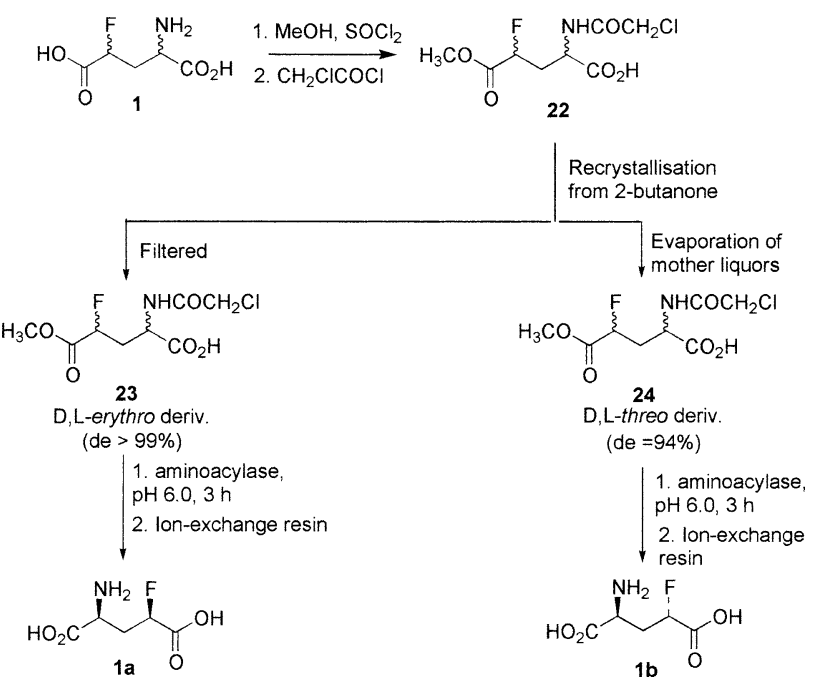

Scheme 5. Preparation of L-erythro and L-threo-4-fluoroglutamic acid $(\mathbf{1 a} \& \mathbf{1 b})$ by aminoacylase resolution 


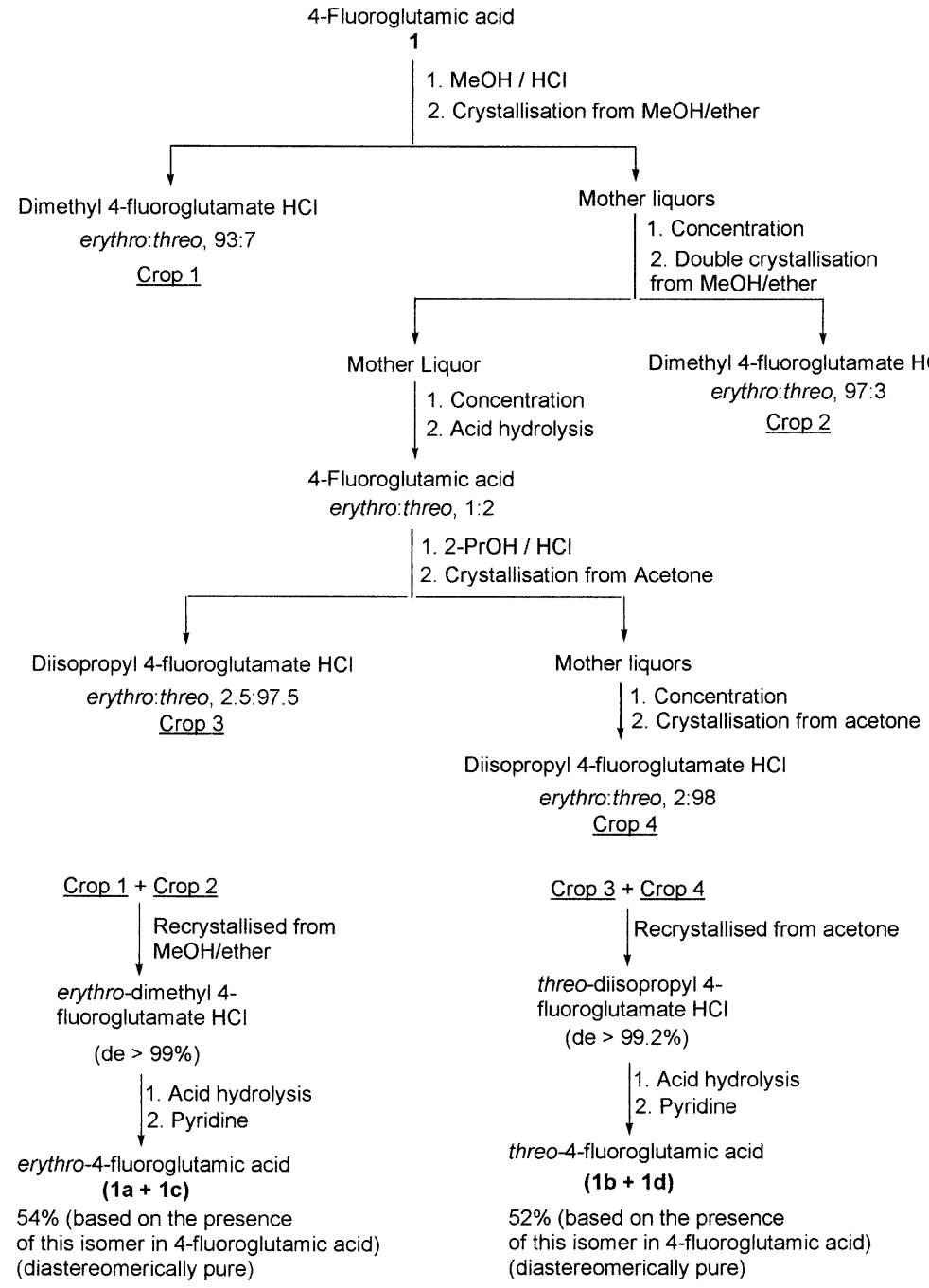

Fig. 5. Separation of 4-fluoroglutamic acid $\mathbf{1}$ into erythro $(\mathbf{1 a}+\mathbf{1 c})$ and threo $(\mathbf{1 b}+\mathbf{1 d})$ diastereomers
Thus, erythro-4-fluoroglutamic acid $(\mathbf{1 a}+\mathbf{1 c})$ was converted into the diastereomeric salts with cinchonine or cinchonidine. The salt of L-erythro acid was crystallised from $50 \%$ aqueous dioxane with more than $97 \%$ optical purity (crop 1). Mother liquors were concentrated and recrystallised from $50 \%$ aqueous dioxane to afford D-erythro acid salt with $88 \%$ optical purity (crop 2). Mother liquors were again concentrated and systematically crystallised from $50 \%$ aqueous dioxane to give a second crop of L-erythro salt (crop 3) and D-erythro salt (crop 4) with $98 \%$ and 95.5\% optical purity, respectively. The combined crop of L-erythro salt (crop 1 and 3) and D-erythro salt (crop 2 and 4) were individually released from their chiral auxiliary to afford L-erythro and D-erythro-4fluoroglutamic acids in $100 \%$ and $97.5 \%$ optical purity, respectively (Fig. 6). Overall yields of L-erythro and D-erythro acids were 70.2 and $47 \%$, respectively, based on the presence of these enantiomers in erythro4-fluoroglutamic acid $(\mathbf{1 a}+\mathbf{1 c})$ (Tolman and Simek, 2000).

Attempts to resolve threo-4-fluoroglutamic acid (1b $+\mathbf{1 d}$ ) in non-derivatised form with chiral amines were unsuccessful. However, this turned out to be possible with quinine by converting threo acid into the $\mathrm{N}$-acetyl derivative.

In an earlier publication, Tolman reported the isolation of enantiomerically pure D-threo-4fluoroglutamic acid 1d from its racemic threo isomer using brucine as the resolving agent. The overall yield and detailed experimental procedure were not given (Tolman et al., 1985).

The quinine N-acetyl L-threo-4-fluoroglutamate was obtained with more than $92 \%$ optical purity by crystallisation from water. One additional crystallisation enhanced the optical purity to more than $98 \%$. 


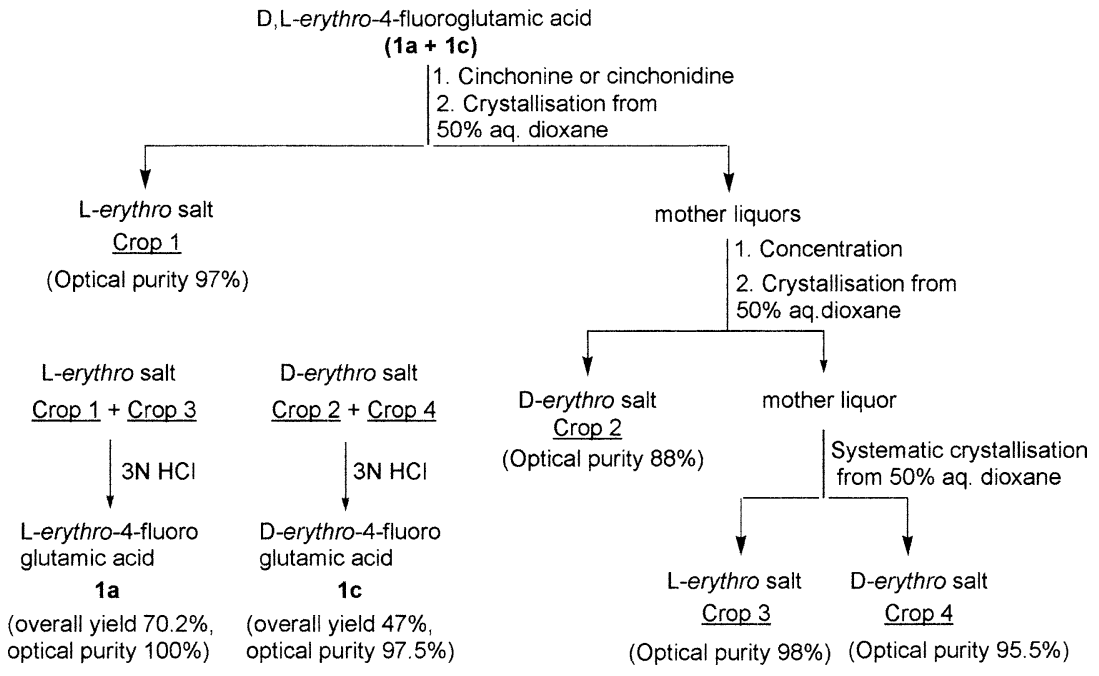

Fig. 6. Resolution of erythro 4-fluoroglutamic acid $(\mathbf{1 a}+\mathbf{1 c})$ with chiral bases

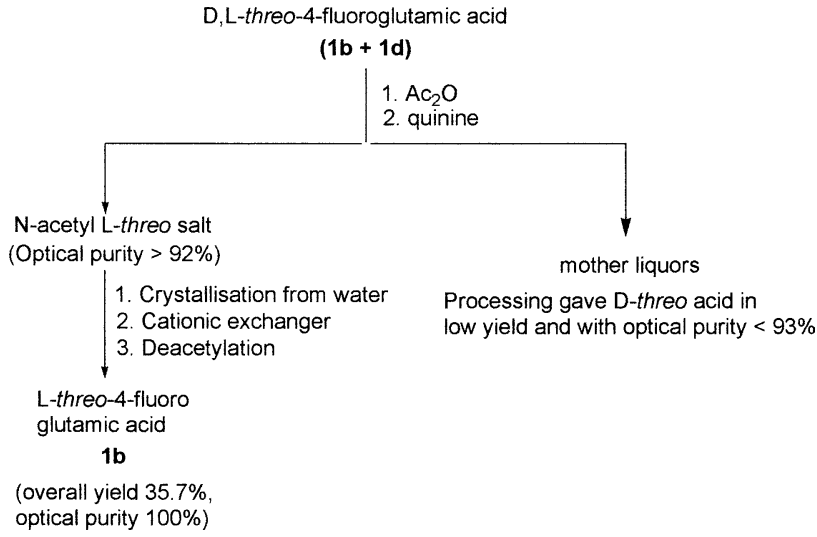

Fig. 7. Resolution of threo 4-fluoroglutamic acid $(\mathbf{1 b}+\mathbf{1 d})$ with chiral base

Cationic exchange purification followed by deacetylation under acidic conditions afforded optically pure L-threo acid $\mathbf{1 b}$ in $35.7 \%$ overall yield based on threo4-fluoroglutamic acid (1b + 1d) (Fig. 7). However, processing of the mother liquors obtained from the isolation of the quinine salt of L-threo acid yielded D-threo acid 1d in low yield and optical purity less than $93 \%$ (Tolman and Simek, 2000).

As a result, an enzymatic approach was explored for the preparation of D-threo-4-fluoroglutamic acid 1d. Enzymatic decarboxylation of racemic threo-4-fluoroglutamic acid $(\mathbf{1 b}+\mathbf{1 d})$ with glutamate decarboxylase gave enantiomerically pure D-threo acid 1d and $S$-4-amino-2-fluorobutyric acid $S$-25 in 87 and $83 \%$ yield, respectively (Scheme 6). This method was also extended to the preparation of D-erythro isomer 1c (Tolman and Sedmera, 2000).

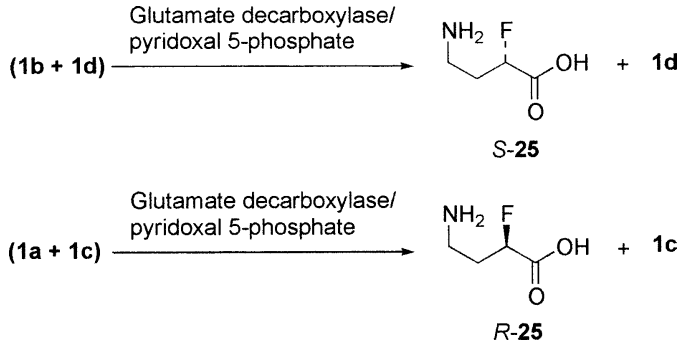

Scheme 6. Enzymatic resolution of D-erythro and D-threo-4fluoroglutamic acid (1c \& 1d)

The optical purities of the compounds were determined by gas chromatography following chiral separation of the four stereomers of 4-fluoroglutamic acid as their $\mathrm{N}-(1 R, 2 S, 5 R)$-menthyloxycarbonyl-Omethyl ester derivatives.

1.1.2.2 Stereoselective synthesis from the chiral pool

The four stereomers of 4-fluoroglutamic acid (1a-1d) have been synthesised using chiral hydroxyprolines and pyroglutaminol as starting materials.

\section{a) Using hydroxyprolines}

Hudlicky developed the synthesis of all four stereomers of 4-fluoroglutamic acid (1a-1d) using commercially available trans-4-hydroxy-L-proline $\mathbf{2 6}$ and cis-4-hydroxy-D-proline 27.

The authors first prepared L-threo and D-erythro4-fluoroglutamic acid $\mathbf{1 b}$ and $\mathbf{1 c}$ from commercially available trans- and cis-4-hydroxyprolines $\mathbf{2 6}$ and $\mathbf{2 7}$, respectively. The synthetic pathway for $\mathbf{1 b}$ involved acetylation of trans-4-hydroxy-L-proline $\mathbf{2 6}$, followed 


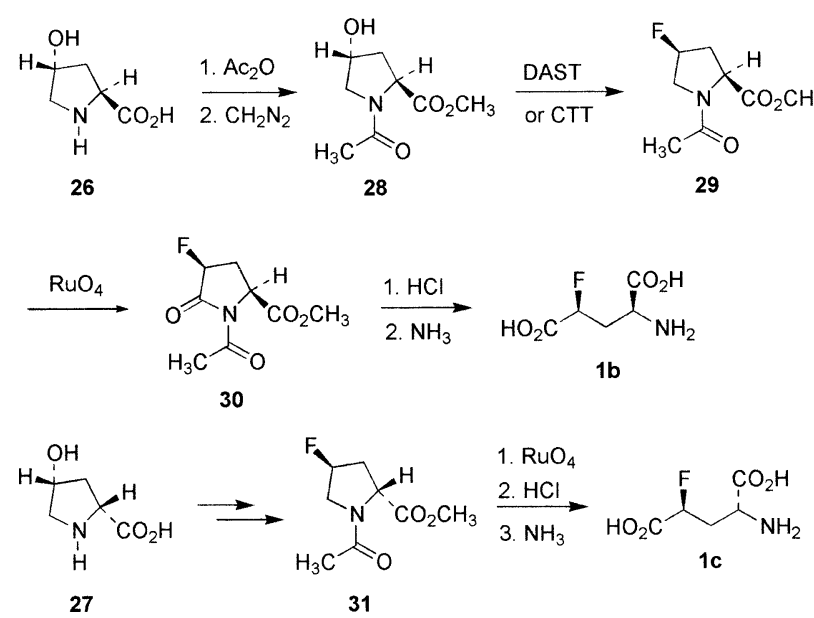

Scheme 7. Stereospecific synthesis of L-threo and D-erythro-4fluoroglutamic acid (1b \& 1c)

by esterification with diazomethane to afford methyl 1acetyl-trans-4-hydroxy-L-prolinate 28. Fluorination of the latter with diethylaminosulfur trifluoride (DAST) or with 2-chloro-1,1,2-trifluorotriethylamine gave cismethyl 1-acetyl-4-fluoro-L-prolinate $\mathbf{2 9}$ in $50 \%$ yield, exhibiting conformational isomerism. Rutheniummediated oxidation afforded methyl 1-acetyl-cis-4fluoro-1-pyrrolidin-5-one-2-carboxylate $\mathbf{3 0}$ in $46 \%$ yield. Acid hydrolysis of this pyroglutamate derivative gave L-threo-4-fluoroglutamic acid $\mathbf{1 b}$ in $18 \%$ overall yield based on 26 (Scheme 7). Following the same route, D-erythro-4-fluoroglutamic acid $\mathbf{1 c}$ was obtained from cis-4-hydroxy-D-proline $\mathbf{2 7}$ in a $13 \%$ overall yield (Hudlicky and Merola, 1990 and 1991).

Conformational isomerism, also observed with the fluoro derivative 31, was later explained by Young using variable temperature ${ }^{1} \mathrm{H}$ NMR (Avent et al., 1992).

The authors also described their efforts to develop a stereospecific synthesis of L-threo-4-fluoroglutamic acid $\mathbf{1 b}$ using N-tert-butoxycarbonyl-L-pyroglutamate 32 as the chiral starting material. The protected pyroglutamate was stereospecifically converted into the $(2 S, 4 R)$ alcohol $\mathbf{3 3}$ in $30 \%$ yield, after refining Ohta's procedure (Ohta et al., 1988). The alcohol was subjected to fluorination with DAST to give cis-4fluoro derivative $\mathbf{3 4}$ in $40 \%$ yield (Scheme 8). The authors did not, however, hydrolyse the fluorinated pyroglutamate derivative $\mathbf{3 4}$ given the fact that the analogous compound $\mathbf{3 0}$ had been previously converted to L-threo-4-fluoroglutamic acid $\mathbf{1 b}$.

Later, Hudlicky extended this strategy to the preparation of D-threo and L-erythro isomers 1d and 1a.
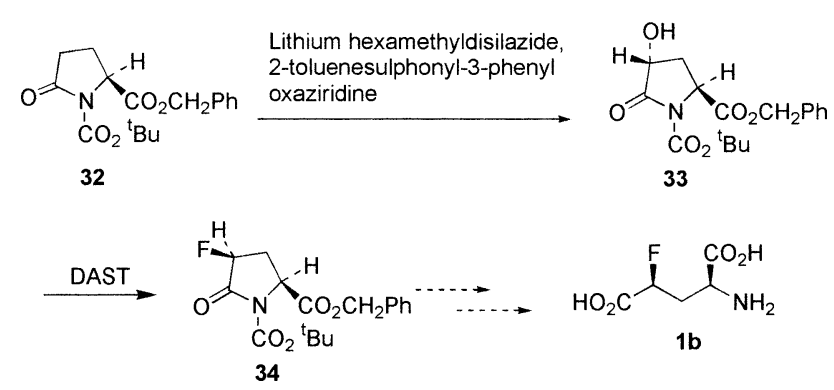

Scheme 8. Stereospecific synthesis of a precursor of L-threo-4fluoroglutamic acid $\mathbf{1 b}$

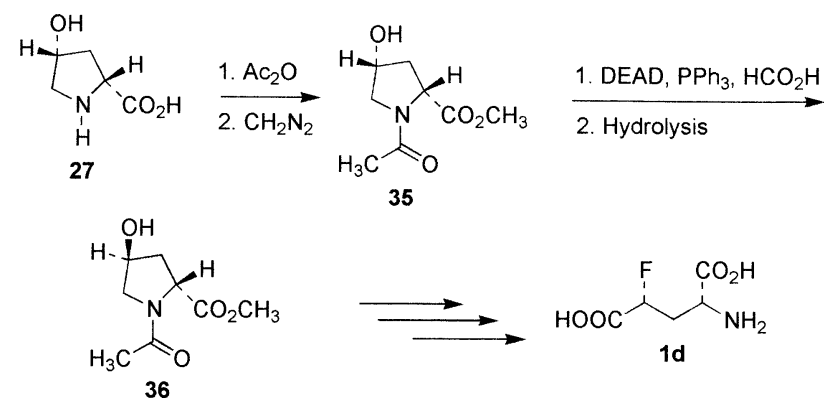

Scheme 9. Stereospecific synthesis of D-threo-4-fluoroglutamic acid 1d

trans-4-Hydroxy-D-proline 36 and cis-4-hydroxy-Lproline 40, the key intermediates for the synthesis of D-threo and L-erythro isomer were prepared from commercially available cis-4-hydroxy-D-proline $\mathbf{2 7}$ and trans-4-hydroxy-L-proline 26, respectively.

$\mathrm{N}$-acetylation and diazomethane esterification of cis-4-hydroxy-D-proline $\mathbf{2 7}$ gave 35, which under Mitsunobu conditions afforded $\mathrm{N}$-acetyl trans-4hydroxy-D-proline methyl ester $\mathbf{3 6}$ by configuration inversion at carbon 4 of the pyrrolidine ring (Scheme 9). The yield of this reaction was $21-37 \%$ (Hudlicky, 1993). 36 was then converted to D-threo-4fluoroglutamic acid 1d following the same reaction sequence, reported previously (Hudlicky and Merola, 1990 and 1991).

For the synthesis of L-erythro-4-fluoroglutamic acid 1a, cis-4-hydroxy-L-proline $\mathbf{4 0}$ was prepared from 1-benzyloxycarbonyl-trans-4-hydroxy-L-proline 37 using the oxidation-reduction sequence depicted in Scheme 10. Oxidation with chromium trioxide afforded the 4-keto derivative $\mathbf{3 8}$ which on stereospecific reduction with sodium borohydride gave 1-benzyloxycarbonyl-cis-4-hydroxy-L-proline 39. Following deprotection, cis-4-hydroxy-L-proline $\mathbf{4 0}$ was obtained in $22 \%$ overall yield based on $\mathbf{2 6 . 4 0}$ was 

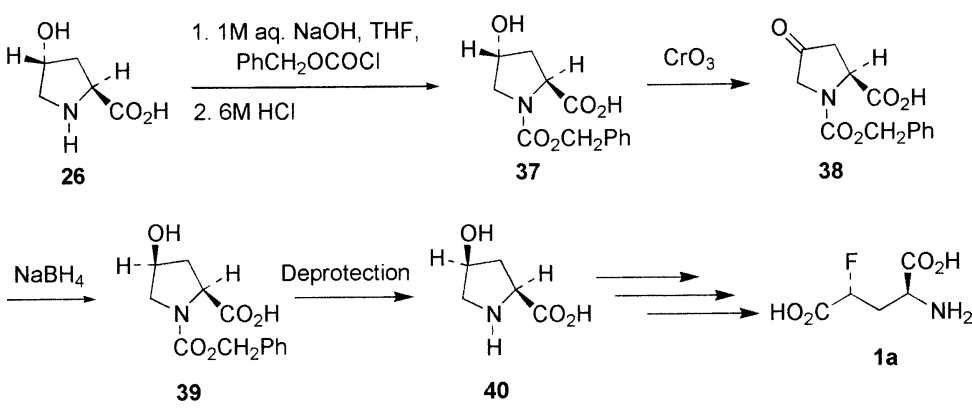

Scheme 10. Stereospecific synthesis of L-erythro-4fluoroglutamic acid 1a
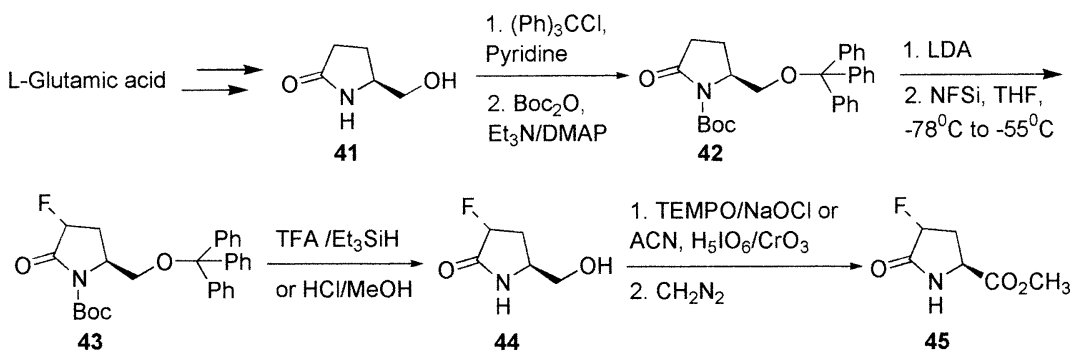<smiles>CC1CO1</smiles>

converted to L-erythro-4-fluoroglutamic acid $\mathbf{1 a}$ in a $2 \%$ overall yield using the standard protocol (Hudlicky, 1991).

\section{b) Using pyroglutaminol}

Coward and Konas synthesised L-erythro-4fluoroglutamic acid 1a using L-pyroglutaminol 41 which is commercially available or easily prepared from L-glutamic acid by Pickering's procedure (Pickering et al., 1994). The key step of the synthesis was the diastereoselective electrophilic fluorination of the pyroglutamic acid derivative $\mathbf{4 2}$ with $\mathrm{N}$ fluorobenzenesulphonimide (NFSi), which gave a single isomer of 3-fluoro-protected pyroglutaminol 43 as revealed by ${ }^{1} \mathrm{H}$ and ${ }^{19} \mathrm{~F}$ NMR analyses of the crude reaction mixture. Complete deprotection of the hydroxyl and amino groups gave the fluorinated pyroglutaminol derivative 44. Oxidation of $\mathbf{4 4}$, followed by diazomethane esterification gave the 4fluoropyroglutamate derivative 45 (Scheme 11). Acid hydrolysis of $\mathbf{4 5}$ followed by neutralisation with propylene oxide afforded L-erythro-4-fluoroglutamic acid $1 a$ in $18 \%$ overall yield based on $\mathbf{4 1}$ (Konas and Coward, 2001).

\subsection{Syntheses of 4-fluoroglutamine 2}

The reported chemistry of 4-fluoroglutamine $\mathbf{2}$ is not as vast as that of 4-fluoroglutamic acid $\mathbf{1}$. The first
Scheme 11. Diastereoselective synthesis of L-erythro-4-fluoroglutamic acid 1a synthesis of 4-fluoroglutamic $\mathbf{1}$ appeared in 1960 and it was only three years later that the first report on the synthesis of $\mathbf{2}$ appeared in the literature. To date, the only synthetic route to 4-fluoroglutamine obtained as a mixture of stereoisomers and as a diastereomeric racemate of erythro and threo forms starts from the corresponding 4-fluoroglutamic acid.

\subsubsection{Preparation of 4-fluoroglutamine 2 as a mixture of stereoisomers}

In an early synthesis, Tolman prepared 4fluoroglutamine $\mathbf{2}$ by regioselective esterification of the $\gamma$-carboxyl group followed by aminolysis. The $\gamma$-carboxyl group of 4-fluoroglutamic acid $\mathbf{1}$ was esterified with methanolic hydrochloric acid in $41.5 \%$ yield. The aminolysis of the resulting $\gamma$-ester derivative 46 by ammonia in the presence of carbon disulfide as $\alpha$-amino protecting group gave 4fluoroglutamine $\mathbf{2}$ in only $28 \%$ yield (Tolman, 1964) (Scheme 12).

Later, Tolman and Veres improved the overall yield of 4-fluoroglutamine $\mathbf{2}$ using basically the same synthetic path, but slightly different conditions. In the revised procedure, 1 was esterified with methanol in the presence of thionyl chloride to afford $\gamma$-methyl ester derivative 46 in $58 \%$ yield. Aminolysis of the ester with methanolic ammonia in the presence of carbon 

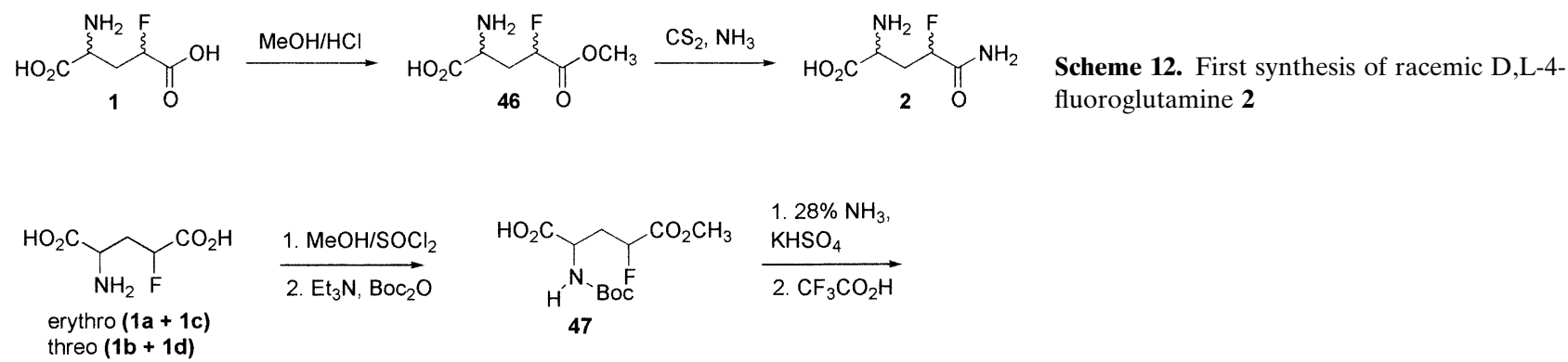

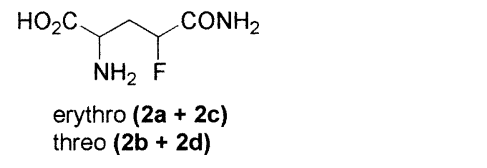

disulfide afforded 4-fluoroglutamine 2 in $36 \%$ yield (Tolman and Veres, 1967). The importance of amino group protection of the $\gamma$-ester derivative of 4fluoroglutamic acid was recognised when aminolysis of the monoester of 4-fluoroglutamic acid $\mathbf{4 6}$ gave a mixture of cis and trans-4-fluoro-5-pyrrolidone-2carboxylic acids (Tolman et al., 1993).

\subsubsection{Preparation of diastereomeric}

4-fluoroglutamine $(\mathbf{2 a}+\mathbf{2 c} \& \mathbf{2 b}+\mathbf{2 d})$

After their successful separation of erythro and threo4-fluoroglutamic acid (Tolman, 1993; Tolman et al., 1993), Tolman and Sedmera converted them to the corresponding diastereomeric 4-fluoroglutamine. Racemic erythro and threo-4-fluoroglutamic acid were individually converted into their 5-methyl ester hydrochloride salt with thionyl chloride and methanol. Temporary protection of the amino group as the tertbutyloxycarbonyl derivative $\mathbf{4 7}$ followed by aminolysis with $28 \%$ aqueous ammonia gave N-protected 4fluoroglutamine. Release of the protecting group with TFA gave erythro-4-fluoroglutamine $(\mathbf{2 a}+\mathbf{2 c})$ and threo-4-fluoroglutamine $(\mathbf{2 b}+\mathbf{2 d})$ in $35 \%$ and $39 \%$ overall yields based on the corresponding diastereomeric erythro and threo-4-fluoroglutamic acid, respectively (Tolman and Sedmera, 2000) (Scheme 13).

It is worth noting that the same transformations have not yet been applied to the synthesis of enantiomerically pure 4-fluoroglutamine (2a-2d) despite the available procedures for the preparation of all four stereomers of 4-fluoroglutamic acid (1a-1d).
Scheme 13. Tolman's synthesis of erythro and threo-4fluoroglutamine $(\mathbf{2 a}+\mathbf{2 c}) \&(\mathbf{2 b}+\mathbf{2 d})$

\section{Syntheses of 4,4-difluoroglutamic acid 48 and 4,4-difluoroglutamine 49}

Replacement of the two $\gamma$-hydrogens of glutamic acid and glutamine with fluorine atoms gives the corresponding 4,4-difluoroglutamic acid $\mathbf{4 8}$ and 4,4difluoroglutamine $\mathbf{4 9}$, respectively, in the two possible enantiomeric forms.

\subsection{4,4-Difluoroglutamic acid $\mathbf{4 8}$}

The chemistry of 4,4-difluoroglutamic acid $\mathbf{4 8}$ evolved very late compared to $\gamma$-fluoroglutamic acid 1. 4,4Difluoroglutamic acid $\mathbf{4 8}$ was prepared in racemic form by nitroaldol reaction and in optically active form by asymmetric syntheses using either a chiral acryloxazolidinone derivative, an L-pyroglutaminol or an L-serine aldehyde equivalent as chiral building blocks.

\subsubsection{Syntheses of D,L-4,4-difluoroglutamic acid $\mathbf{4 8}$}

After synthesising and investigating the FPGS substrate properties of 4-fluoroglutamic acid, and 3,3difluoroglutamic acid as glutamate surrogates (Licato et al., 1990; Hart et al., 1996), Coward and co-workers switched to the synthesis of racemic D,L-4,4difluoroglutamic acid $\mathbf{4 8}$ to explore similar biological properties. The authors also realized that 4,4difluoroglutamic acid $\mathbf{4 8}$ could prove useful for the preparation of the MTX analogue, 4,4-F2MTX, to investigate the biochemical reactions catalyzed by folate-dependent enzymes and its effects on cell growth.

Ethyl nitroacetate $\mathbf{5 0}$ was subjected to nitroaldol reaction with the difluorinated hemiacetal $\mathbf{5 1}$ to give 


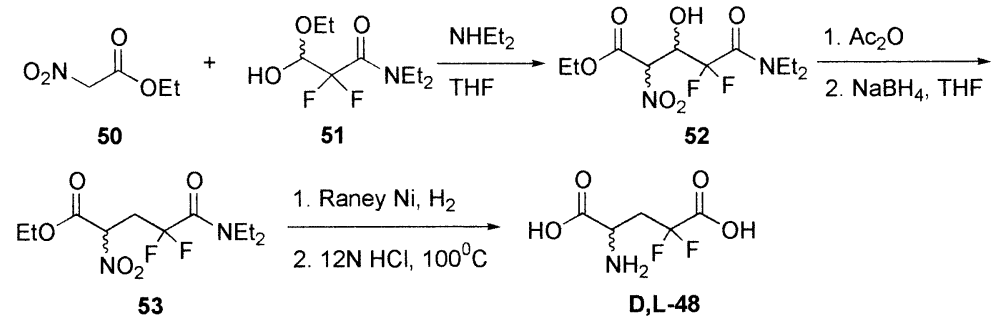

Scheme 14. Synthesis of D,L-4,4-difluoroglutamic acid D,L-48 by nitroaldol reaction

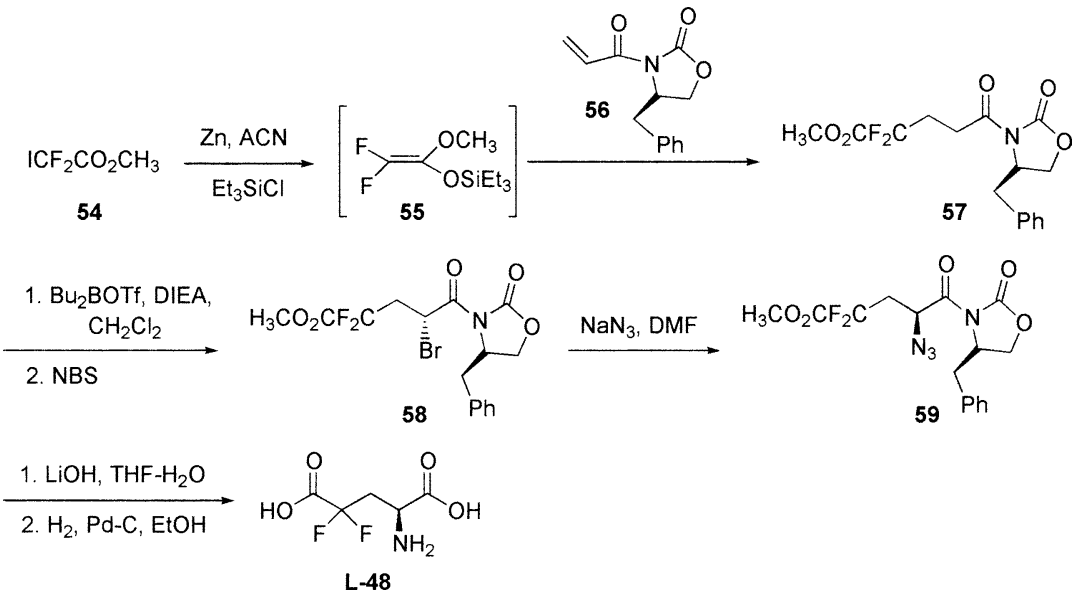

Scheme 15. Asymmetric synthesis of L-4,4difluoroglutamic acid $\mathbf{L - 4 8}$ the nitro alcohol adduct $\mathbf{5 2}$ which after acetylation and subsequent deoxygenation afforded 53. This chromatographically pure product underwent hydrogenation on Raney nickel followed by acid hydrolysis and anion-exchange purification to give $\mathrm{D}, \mathrm{L}-4,4-$ difluoroglutamic acid D,L-48 in 37\% overall yield based on 51 (Tsukamoto et al., 1996) (Scheme 14).

D,L-48 slightly inhibited the FPGS-catalysed reaction suggesting that it was either a poor alternate substrate or a weak reversible inhibitor of FPGS. In fact, although D,L-48 is less reactive than Glu, it indeed serves as an alternate substrate for FPGScatalysed polyglutamylation. In other biological studies, D,L-4,4-difluoroglutamic acid D,L-48 was converted to 4,4-F2MTX employing the Piper and Montgomery procedure (Piper and Montgomery, 1977). By comparison with the substrate behaviour of MTX, it was found that 4,4-F2MTX binds poorly to FPGS and is neither a substrate nor an inhibitor of FPGS.

\subsubsection{Synthesis of optically active} 4,4-difluoroglutamic acid

a) Michael addition. Taguchi synthesised L-4,4difluoroglutamic acid $\mathbf{L - 4 8}$ after coming across a report on chemically modified antitumor agent methotrexate (FMTX) containing 4-fluoroglutamic acid 1 (Tsushima et al., 1988). They extended the Michael addition of 2,2-difluoroketene silyl acetal $\mathbf{5 5}$ to $\alpha, \beta$-unsaturated carbonyl compounds or acetals for asymmetric synthesis of L-4,4-difluoroglutamic acid L-48. The key substrate in the methodology, 2,2difluoroketene silyl acetal 55, was generated in situ by reaction of methyl difluoroiodoacetate 54 with zinc and triethylchlorosilane. 1,4-Addition of $\mathbf{5 5}$ to $R$ acryloxazolidinone derivative $\mathbf{5 6}$ gave $\mathbf{5 7}$ in $40 \%$ yield. NBS-bromination of the Z-boron enolate (resulting from dibutylboron triflate/DIEA treatment of 57) followed by azide displacement of the resulting bromide derivative $\mathbf{5 8}(2 R / 2 S=8.6)$ gave $\mathbf{5 9}$ in $64 \%$ yield. Hydrolysis of the ester and imide groups of the major $2 S$-isomer of $\mathbf{5 9}$ and subsequent hydrogenation afforded L-4,4-difluoroglutamic acid L-48 in 74\% yield (Scheme 15). Using the same reaction sequence, D4,4-difluoroglutamic acid D-48 was prepared from the $(S)$-enantiomer of acryloyloxazolidinone derivative for optical purity determination. Both enantiomers of 4,4-difluoroglutamic acid were optically pure as revealed by ${ }^{1} \mathrm{H}$ NMR of the $(S)$-MTPA-Mosher's amides of their dimethyl ester derivatives (Kitagawa et al., 1990, Kobayashi et al., 1991). 
b) Electrophilic fluorination. Since initial biological results with racemic acid $\mathbf{4 8}$ were not informative enough, Coward and Konas pursued their quest for stereochemically pure L-4,4-difluoroglutamic acid L-48 using electrophilic difluorination of the enantiomerically pure bicyclic lactam $\mathbf{6 0}$ conveniently prepared from L-pyroglutaminol $\mathbf{4 1}$ (commercially available or easily obtained according to the literature (Pickering et al., 1994)). Amino acetalisation of 41 with DMP gave the bicyclic lactam 60. Two-step electrophilic fluorination of the lactam $\mathbf{6 0}$ with NSFi gave successively mono then difluorinated product 61, which was cleaved with acetic acid in aqueous acetonitrile to yield L-difluoropyroglutaminol $\mathbf{6 2}$. Jones oxidation of $\mathbf{6 2}$ gave the difluoropyroglutamate carboxylate intermediate which on acid hydrolysis followed by neutralisation and crystallisation provided L-4,4-difluoroglutamic acid L-48 in $12 \%$ overall yield based on 41 (Konas and Coward, 1999 and 2001) (Scheme 16).

c) Reformatsky reaction. Richards synthesised L-4,4difluoroglutamic acid $\mathbf{L - 4 8}$ using the configurationally stable L-serine aldehyde equivalent $\mathbf{6 4}$ as the chiral building block, which was prepared from N-protected L-serine 63 using Lajoie's procedure (Blaskovich et al., 1998). Reformatsky reaction of ethyl bromodi-

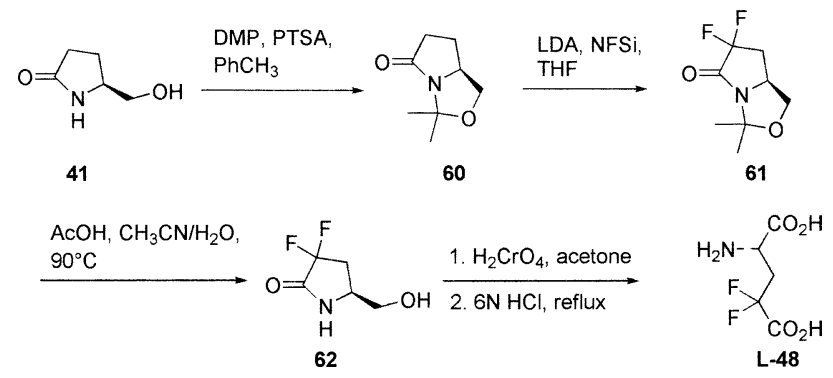

Scheme 16. Synthesis of L-4,4-difluoroglutamic acid L-48 by electrophilic difluorination of enantiomerically pure bicyclic lactam 60
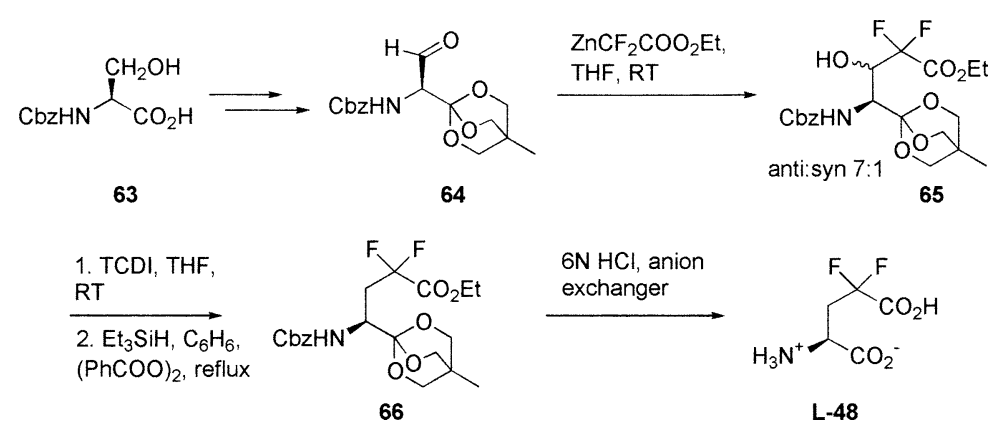

Scheme 17. Synthesis of L-4,4-difluoroglutamic acid L-48 using L-serine equivalent aldehyde 64 fluoroacetate with aldehyde $\mathbf{6 4}$ gave a mixture of anti:syn (7:1) alcohol derivative $\mathbf{6 5}$. The latter diastereomeric mixture was thiocarbonylated before radical-promoted deoxygenation to afford the protected L-4,4-difluoroglutamic acid 66. Acid hydrolysis of the deoxygenated product $\mathbf{6 6}$ followed by anion exchange chromatography gave optically pure L-4,4difluoroglutamic acid $\mathbf{L}-\mathbf{4 8}$ in $44 \%$ overall yield based on 64 (Scheme 17). Optical purity was determined by comparison with the reported specific rotation values (Ding et al., 2001).

\subsection{4,4-Difluoroglutamine 49}

The conversion of racemic 4,4-difluoroglutamic acid 48 into the corresponding 4,4-difluoroglutamine 49 was accomplished only during the last decade. Two syntheses of 4,4-difluoroglutamine $\mathbf{4 9}$ have been reported so far: the first is racemic while the second is in the $\mathrm{L}$ series.

\subsubsection{Synthesis of D,L-4,4-difluoroglutamine 49}

Coward and Tsukamoto converted D,L-4,4difluoroglutamic acid $\mathbf{4 8}$ into the N-protected benzyloxycarbonyl derivative $\mathbf{6 7}$ which was esterified with isobutylene to give the fully protected acid derivative 68. The enhanced electrophilic character of the $\gamma$ carbonyl in 68 which is due to the two adjacent fluorine atoms resulted in the regioselective aminolysis of the $\gamma$-carboxyl ester. Routine deprotection of amino and carboxyl groups of the amide derivative 69 yielded D,L-difluoroglutamine 49 in 29\% overall yield based on 48 (Tsukamoto and Coward, 1996) (Scheme 18).

\subsubsection{Synthesis of N-Boc-L-4,4-difluoroglutamine $\mathbf{7 5}$}

Recently, Meffre reported the first synthesis of N-Boc protected L-4,4-difluoroglutamine $\mathbf{7 5}$ in high optical 


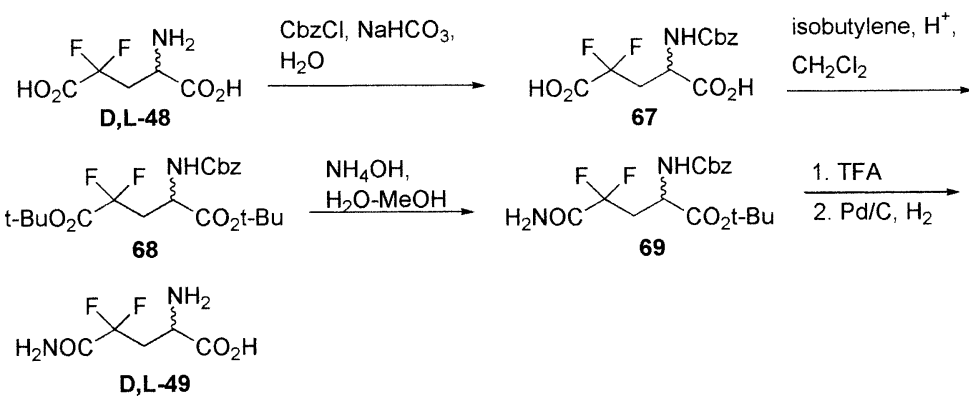

Scheme 18. First synthesis of D,L-4,4-difluoroglutamine 49

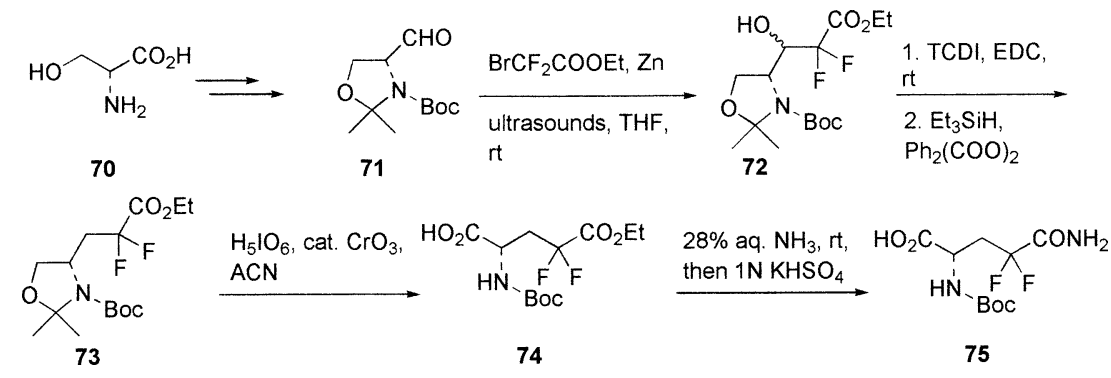

Scheme 19. First synthesis of N-Boc-L4,4-difluoroglutamine $\mathbf{7 5}$ employing (R)Garner's aldehyde purity using (R)-Garner's aldehyde $\mathbf{7 1}$ as a chiral building block. 71, obtained from D-serine $\mathbf{7 0}$ in 5 steps using Garner's and Meffre's procedure (Garner and Park, 1992; Meffre et al., 1994) was subjected to Reformatsky reaction using ethyl bromodifluoroacetate. Thiocarbonylation of the resulting diastereomeric mixture of alcohol derivative $\mathbf{7 2}$ (d.r. = 7:1) with TCDI followed by Barton-McCombie radical reaction gave the deoxygenated derivative 73 . Periodic acid oxidation of $\mathbf{7 3}$ in the presence of catalytic chromium trioxide gave the L-4,4-difluoroglutamic acid derivative 74. Aminolysis of $\mathbf{7 4}$ with aqueous ammonia gave N-Boc-L-4,4-difluoroglutamine $\mathbf{7 5}$ in 24\% overall yield based on 74 (Meffre et al., 2001) (Scheme 19). The optical purity of $\mathbf{7 5}$ was found to be $>99 \%$ as deduced from chiral HPLC analysis.

Acid hydrolysis of the Boc protecting group of $\mathbf{7 5}$ resulted in isolation of a pure compound which exhibited spectroscopic properties compatible with L-4,4-difluoroglutamine L-49. Unfortunately, both microanalysis and electrospray mass spectroscopy analysis in negative mode indicated that deprotection resulted actually in the simultaneous cleavage of the amide group to give L-4,4-difluoroglutamic acid $\mathbf{L}-\mathbf{4 8}$ (Meffre et al., 2002). The facile hydrolytic cleavage of the amide group, which was not noticed in the synthesis of D,L-4,4-difluoroglutamine D,L-49, likely results from the strong electronegativity of the two adjacent fluorine atoms. This problem might be circumvented using other amino protecting groups, which could be cleaved under non-hydrolytic conditions. But before L-4,4-difluoroglutamine $\mathbf{L}-\mathbf{4 9}$ can be prepared and used for biological studies, a number of questions regarding the stability of this compound must be answered.

\section{Concluding remarks}

4-Fluoroglutamic acid $\mathbf{1}$ has attracted the attention of biochemists because of its antimetabolic properties (Tolman and Veres, 1966; Drsata et al., 1999 and 2000). Its use as an alternative substrate to lead to a fluorinated analogue of the antitumor agent methotrexate emphasised the possibilities of obtaining clinically more potent analogues, particularly to treat patients developing drug resistance (Licato et al., 1990).

4-Fluoroglutamic acid $\mathbf{1}$ as a mixture of racemic diastereomers was prepared by different methodologies, the original method using a Michael reaction developed by Hudlicky and optimized by Tolman being more practical and elegant for large scale preparations. 4-Fluoroglutamic acids (1a-1d) of different optical purities can be obtained via various resolution techniques such as preferential crystallisation or ion-exchange chromatography coupled with enzymatic separation. As resolution methods demand time and patience for optimisation, chemists generally 
prefer the asymmetric synthesis approach. Asymmetric syntheses for preparation of all four stereoisomers were reported using commercially available hydroxyprolines and pyroglutaminol. The overall yield of enantiomerically pure 4-fluoroglutamic acid is at best $18 \%$. There is then obviously a need for improved access to optically pure 4-fluoroglutamic acid 1. The extremely high costs of L-erythro, Derythro and D-threo-4-fluoroglutamic acids (1a, 1c \& 1d) should stimulate research in that direction.

As a corollary, there is also keen interest in the syntheses of $\gamma$-fluorinated glutamines, for example, in order to investigate whether the Gn-AT could employ this unnatural amino acid as a nitrogen source in place of glutamine. These fluorinated glutamine analogues might help to trap and structurally characterise specific intermediates formed during the amide nitrogen transfer.

4-Fluoroglutamine $\mathbf{2}$ was prepared as a mixture of stereoisomers and as diastereomeric erythro and threo forms from the corresponding 4-fluoroglutamic acid using conventional protection / aminolysis / deprotection approaches. In spite of the fact that all four stereoisomers of 4-fluoroglutamic acid (1a-1d) have been prepared, none of them has been converted into the corresponding enantiomerically pure 4fluoroglutamine (2a-2d). L-erythro-4-fluoroglutamine 2a which is not described in the literature is nevertheless commercially available, though very expensive.

Racemic 4,4-difluoroglutamic acid D,L-48 was prepared by nitroaldol reaction while its L-enantiomer could be prepared by Michael addition of 2,2difluoroketene silyl acetal $\mathbf{5 5}$ to $(R)$-acryloyloxazolidinone $\mathbf{5 6}$ or by electrophilic fluorination of appropriately substituted enantiomeric lactam 60. A recent method reported by Richards involving Lserine equivalent aldehyde 64 as a chiral building block seems to be a more promising approach for preparing L-4,4-difluoroglutamic L-48.

Racemic 4,4-difluoroglutamic acid D,L-48 was converted to the corresponding glutamine D,L-49 using the amino protection, aminolysis and subsequent deprotection strategy. L-4,4-Difluoroglutamine L-49 as the N-Boc derivative $\mathbf{7 5}$ is obtained in an elegant way directly from $(R)$-Garner's aldehyde $\mathbf{7 1}$ using the Reformatsky reaction as a key step.

As mentioned above, hydrolytic cleavage of N-Boc protecting group did not lead to L-4,4difluoroglutamine L-49 but to L-4,4-difluoroglutamic acid L-48. The high sensitivity of the amide bond of L-49 to hydrolytic conditions likely explains the lack of data concerning its biological applications despite a strong reported interest in this glutamine analogue.

As reported in literature, the chemical reactivity of these biologically important compounds changes significantly due to the presence of adjacent fluorine atoms. Therefore, there is still a strong demand for efficient enantio and diastereoselective syntheses of $\gamma$ fluorinated derivatives of glutamic acid and glutamine as well as other fluorinated analogues. There is little doubt that that these compounds will find interesting biochemical and pharmacological applications in the future.

\section{Acknowledgement}

The authors thank CNRS (FRANCE) for financial support to R. D., Dr R. Dodd for careful reading and improving the quality of the manuscript and all the dedicated co-workers whose names appear in the references

\section{References}

Alekseeva LV, Lundin BN, Burde NL (1967) Synthesis and investigation of compounds with potential biological activity I. Synthesis of 4-fluoroglutamic acid. Zh Obshch Khim 37: 17541755

Ardawi MSM, Newsholme EA (1983) Glutamine metabolism in lymphocyte of the rat. Biochem J 212: 835-842

Avent AG, Bowler AN, Doyle PM, Marchand CM, Young DW (1992) Stereospecific synthesis of 4-fluoroglutamic acids. Tetrahedron Lett 33: 1509-1512

Bergmann ED, Chun-Hsu L (1973) Organic fluorine compounds; Part XLVI. $\gamma$-Fluoroglutamic acid and fluorofolic acid. Synthesis: 44-46

Bergmann ED, Cohen S, Shani A (1963) Organic fluorine compounds. Part XXX. Experiments in the fluoroglutaric acid series. Israel J Chem 1: 79-85

Blaskovich MA, Evindar G, Rose NGW, Wilkinson S, Luo Y, Lajoie GA (1998) Stereoselective synthesis of threo and erythro $\beta$-hydroxy and $\beta$-disubstituted- $\beta$-hydroxy $\alpha$-amino acids. J Org Chem 63: 3631-3646

Bory S, Dubois J, Gaudry M, Marquet A (1984) Resolution of $\gamma$ methyl and $\gamma$-fluoroglutamic acids. Lack of stereospecificity of leucine aminopeptidase with L-leucyl-L-erythro- $\gamma$-substituted glutamates. J Chem Soc Perkin Trans 1: 475-480

Buchanan RL, Dean FH, Pattison FLM (1962) $\gamma$-Fluoroglutamic acid. Can J Chem 40: 1571-1575

Castell LM, Newsholme EA (2001) The relation between glutamine and the immunodepression observed in exercise. Amino Acids 20: 49-61

Ding Y, Wang J, Abboud K, Xu Y, Dolbier W, Richards N (2001) Synthesis of L-4,4-difluoroglutamic acid via nucleophilic addition to a chiral aldehyde. J Org Chem 66: 6381-6188

Drsata J, Netopilova M, Tolman V (1999) Stereoisomers of 4fluoroglutamic acid: influence on Escherichia coli glutamate decarboxylase. Pharmazie 54: 713-714 
Drsata J, Netopilova M, Tolman V (2000) Influence of stereoisomers of 4-fluoroglutamate on rat brain glutamate decarboxylase. J Enzyme Inhibition 15: 273-282

Dubois J, Gaudry M, Bory S, Azerad R, Marquet A (1983) Vitamin K-dependent carboxylation. Study of the hydrogen abstraction stereochemistry with $\gamma$-fluoroglutamic acid-containing peptides. J Biol Chem 258: 7897-7899

Garner P, Park J (1992) 1,1-Dimethylethyl (S)- or (R)-4-formyl-2,2dimethyl-3-oxazolidinecarboxylate: a useful serinal derivative. Org Synth 70: 18-28

Hart B, Haile W, Licato N, Bolanowska W, McGuire J, Coward J (1996) Synthesis and biological activity of folic acid and methotrexate analogues containing L-threo-(2S,4S)-4-fluoroglutamic acid and DL-3,3-difluoroglutamic acid. J Med Chem 39: $56-65$

Haufe G, Kroger S (1996) Syntheses of $\gamma$-fluoro- $\alpha$-amino acids. Amino Acids 11: 409-424

Hudlicky M (1960) The synthesis of $\gamma$-fluoroglutamic acid. Tetrahedron Lett 1: 21-22

Hudlicky M (1961) Organic compounds of fluorine. II. Fluorinated amino acids. Coll Czech Chem Commun 26: 1414-1421

Hudlicky M (1991) Stereospecific synthesis of (+)-L-erythro-4fluoroglutamic acid. Tema con variazioni. J Fluorine Chem 54: 194

Hudlicky M (1992) Chemistry of organic fluorine compounds, 2nd edn. Ellis Horwood Ltd., Chichester

Hudlicky M (1993) Stereospecific synthesis of all four stereoisomers of 4-fluoroglutamic acid. J Fluorine Chem 60: 193-210

Hudlicky M, Merola J (1990) New stereospecific syntheses and $\mathrm{X}$-ray diffraction structures of (-)-D-erythro- and (+)-L-threo4-fluoroglutamic acid. Tetrahedron Lett 31: 7403-7406

Hudlicky M, Merola J (1991) Corrigendum. Tetrahedron Lett 32: 3134

Kaneko T, Lee YK, Hanafusa T (1962) Syntheses of $\gamma$ hydroxyglutamic acid. Bull Chem Soc Jpn 35: 875-878

Kitagawa O, Hashimoto A, Kobayashi Y, Taguchi T (1990) Michael addition of 2,2-difluoroketene silyl acetal. Preparation of 4,4difluoroglutamic acid and 5,5-difluorolysine. Chem Lett 13071310

Kobayashi Y, Taguchi T, Kitagawa O, Hashimoto T, Miura A (1991) Preparation of 2,2-difluorocarboxylic acid derivatives. JP03027325

Kokuryo Y, Nakatani T, Kobayashi K, Tamura Y, Kawada K, Ohtani M (1996) Practical synthesis of L-erythro- and L-threo4-fluoroglutamic acids using aminoacylase. Tetrahedron: Asymmetry 7: 3545-3551

Konas DW, Coward JK (1999) Synthesis of L-4,4-difluoroglutamic acid via electrophilic difluorination of a lactam. Org Lett 1: 21052107

Konas DW, Coward JK (2001) Electrophilic fluorination of pyroglutamic acid derivatives: Application of substratedependent reactivity and diastereoselectivity to the synthesis of optically active 4-fluoroglutamic acids. J Org Chem 66: 88318842

Kukhar VP, Soloshonok VA (1995) Fluorine-containing amino acids. Synthesis and properties. John Wiley and Sons, Chichester

Licato NJ, Coward JK, Nimec Z, Galivan J, Bolanowska WE, McGuire JJ (1990) N-[N-(4-deoxy-4-amino-10-methylpteroyl)-4fluoroglutamyl]- $\gamma$-glutamate, an unusual substrate for folylpoly- $\gamma$ glutamate synthetase and $\gamma$-glutamyl hydrolase. J Med Chem 33: 1022-1027

Massiere F, Badet-Denisot M-A (1998) The mechanism of glutamine-dependent amidotransferases. Cell Mol Life Sci 54: 205-222
Maurs M, Ducrocq C, Righini-Tapie A, Azerad R (1985) Gas chromatographic resolution of substituted glutamic acid enantiomers. J Chromatogr 325: 444-449

Meffre P, Dave R, Leroy J, Badet B (2001) A concise synthesis of L-4,4-difluoroglutamine. Tetrahedron Lett 42: 8625-8627

Meffre P, Dave R, Leroy J, Badet B (2002) Corrigendum to "A concise synthesis of L-4,4-difluoroglutamine" Tetrahedron Lett 43: 6279

Meffre P, Durand P, Branquet E, Le Goffic F (1994) A straightforward synthesis of N-Boc-L-serinal and N-Boc-Lthreoninal acetonides. Synth Commun 24: 2147-2152

Ohta T, Hosoi A, Nozoe S (1988) Stereoselective hydroxylation of $\mathrm{N}$-carbamoyl-L-pyroglutamate. Synthesis of $(-)$-Bulgecinine. Tetrahedron Lett 29: 329-332

Pickering L, Malhi BS, Coe PL, Walker RT (1994) The synthesis of $4^{\prime}$-t-butylcarbamyl- and $4^{\prime}$-p-toluenesulphonamidyl-2', $3^{\prime}$ dideoxypyrimidine nucleoside analogues. Nucleosides Nucleotides 13: 1493-1506

Piper JR, Montgomery JA (1977) Preparation of 6-(bromomethyl)2,4-pteridinediamine hydrobromide and its use in improved syntheses of methotrexate and related compounds. J Org Chem 42: 208-211

Sutherland A, Willis CL (2000) Synthesis of fluorinated amino acids. Nat Prod Rep 17: 621-631

Teplyakov A, Leriche C, Obmolova G, Badet B, Badet-Denisot M-A (2002) From Lobry de Bruyn to enzyme-catalyzed ammonia channelling: molecular studies of D-glucosamine-6P synthase. Nat Prod Rep 19: 60-69

Tolman V (1964) Monofluorinated analogues of amino acids. Tetrahedron Lett 5: 1967-1969

Tolman V (1993) Chemistry of 4-fluoroglutamic acid. Part 1. A critical survey of its syntheses: an attempt to optimize reaction conditions for large-scale preparation. J Fluorine Chem 60: 179183

Tolman V (1996) Syntheses of fluorinated amino acids from the classical to the modern concept. Amino Acids 11: 15-36

Tolman V, Sedmera P (2000) Chemistry of 4-fluoroglutamic acid. Part 3. Preparation of the diastereomers of 4-fluoroglutamine and 4-fluoroisoglutamine. An enzymatic access to the antipodes of 4amino-2-fluorobutyric acid. J Fluorine Chem 101: 5-10

Tolman V, Simek P (2000) Chemistry of 4-fluoroglutamic acid. Part 4. Resolution of the racemic erythro and threo forms through their diastereomeric salts. J Fluorine Chem 101: 11-14

Tolman V, Spronglova P (1983) Synthesis of 2-fluoropropenoic acid derivatives. Collect Czech Chem Commun 48: 319-326

Tolman V, Veres K (1964) Synthese und einige reaktionen des 2-fluor-3-hydroxypropionsäure-äthylesters. Collect Czech Chem Commun 29: 234-238

Tolman V, Veres K (1966) Potential antimetabolites derived from 4-fluoroglutamic acid. Tetrahedron Lett 7: 3909-3912

Tolman V, Veres K (1967) Synthesis of certain monofluorinated aliphatic amino acids. Coll Czech Chem Commun 32: 4460-4469

Tolman V, Vlasakova V, Zivny K (1984) Simple method for the separation of diastereomers of 4-fluoroglutamic acid by gas-liquid chromatography. J Chromatogr 315: 421-424

Tolman V, Vlasakova V, Zivny K (1985) Preparative separation of 4-fluoroglutamic acid stereoisomers. J Fluorine Chem 29: 138

Tolman V, Vlasakova V, Nemecek J (1993) Chemistry of 4fluoroglutamic acid. Part 2. Separation of the diastereomers on a large scale. Preparation of cis- and trans-4-fluoro-5-pyrrolidone-2carboxylic acids (4-fluoropyroglutamic acids). J Fluorine Chem 60: $185-191$

Tsukamoto T, Coward J (1996) Facile synthesis of DLdifluoroornithine, DL-4,4-difluoroglutamine, and $\gamma$-DL-4,4- 
difluoroglutamyl-containing peptides: Regiospecific addition of nucleophiles to N-Cbz-di-tert-butyl-DL-4,4-difluoroglutamate. J Org Chem 61: 2497-2500

Tsukamoto T, Kitazume T, McGuire J, Coward J (1996) Synthesis and biological evaluation of DL-4,4-difluoroglutamic acid and DL- $\gamma, \gamma$-difluoromethotrexate. J Med Chem 39: 66-72

Tsushima T, Kawada K, Ishihara S, Uchida N, Shiratori O, Higaki J, Hirata M (1988) Fluorine-containing amino acids and their derivatives. 7. Synthesis and antitumor activity of $\alpha$ - and $\gamma$ substituted methotrexate analogs. Tetrahedron 44: 5375-5387

Unkeless JC, Goldman P (1970) Fluorinated $\gamma$-aminobutyric acid. Enzymatic synthesis and biological activity of a potentially useful analogue. Mol Pharmacol 6: 46-53
Unkeless JC, Goldman P (1971) The diastereomers of $\gamma$ fluoroglutamate: Complementary structural analogues. Mol Pharmacol 7: 293-300

Welch JT (1991) Selective fluorination in organic and bioorganic chemistry, 199th National Meeting of the American Chemical Society, Boston, Masachusetts, 1990, American Chemical Society, Washington, DC

Authors’ address: E-mail: patrick.meffre@unimes.fr 